\title{
LIX. On Dœbereiner's new experiment
}

\section{William Herapath Esq.}

To cite this article: William Herapath Esq. (1823) LIX. On Dœbereiner's new experiment, Philosophical Magazine Series 1, 62:306, 286-289, DOI: $10.1080 / 14786442308644406$

To link to this article: http://dx.doi.org/10.1080/14786442308644406

曲 Published online: 27 Jul 2009.

Submit your article to this journal $\widetilde{ }$

III Article views: 3

Q View related articles $₫$ 
separate; and that this property varies according to the nature of each. 'Those of the metals which would best produce theone effect would not produce the other, or but in a less degree.

We shall abstain from offering some further conjectures to which these singular phrenomena give rise in our minds, until we shall have terminated the experiments which we have undertaken in order to verify them.

\section{On Debereiner's new Experiment. By William Herapath, Esq.*}

October 90,1823 .

THE philosophical publications and newspapers have lately announced an experiment by Dœbereiner with hydrogen gas and platinum in a finely divided state. Those announce. ments were either not accompanied by a description, or by one evidently so inaccurate as to cause chemists in general to treat it as an attempt at the marvellous: the impression made upon my mind was, that Doebereiner himself had not discovered the changes which were effected; and I regret that Mr. Faraday of the Royal Institution did not prosecute his inquiries further than verifying the one experiment.

I therefore made a series of experiments, to make myself acquainted with the phænomena; and, as they throw some light upon the subject, I beg to offer them to this Society for its information : but I shall first premise, that it was before known that oxygen, iodine, chlorine, and sulphur, would, in some cases, where they rapidly united, give out caloric and light sufficient to produce those effects which have been termed ignition and combustion: but no such knowledge had been acquired of hydrogen. Consequently, as this experiment of Doebereiner's appeared to prove that pure hydrogen also had that property, it was of importance that it should be minutely investigated.

Exp. 1. A stream of hydrogen as generated from zinc, \&c., and therefore mixed with common air, was passed upon $5 \mathrm{gr}$. of the spongy mass (as obtained by heating to redness the ammonia-muriate of platinum) in a thin glass capsule; the metal became red hot quite close to the orifice from which the stream issned; but as the gas became purer from the smaller proportion of air, I found it necessary to remove the metal to a little distance; the great heat set fire to the hydrogen; I extinguished it, and occasionally removed the platimun so as to prevent the recurrence of flame. After the experiment had continued half an hour, the metal was examined; there was no

* Read before the Bristol Philosophical Society of Inquirers; and communicated by the Author. 
change in its appenance, nor had it increased or diminished in weight. The phauomenon then, I presume, was not occasioned by any change the metal had undergone. As it was necessary to remove the platinum to a greater distance as the gas became purer, it appeared to indicate that the presence of atmospheric air or oxygen was as essential as the hydrogen : to prove the truth of this idea, a large thin bulb having a hole in its side was blown at the end of a piece of tube ; into which tube hydrogen was conveyed. The platinum was in an atmosphere of hylrogen, but it did not become hot; a fine tube was then introduced into the hole in the bulb, and a stream of common air made to act on the metal; it immediately glowed, and continued to do so as long as both currents were directed towards it, while water was found on the sides of the bulb, which increased as the experiment went on.

Exp. 2. It seemed to result from this, that the platinum has the curious property of causing oxygen and hydrogen to combine at a low heat: I therefore directed a stream of the mixed gases from the gas blowpipe upon a portion of the spongy mass, when it glowed as before and ignited the gases at the jet pipe; but I found that the metal required to be heated a little before the phænomenon occurred: as this was not necessary when hydrogen was admitted direct from the retort, the temperature of the atmosphere being sufficient, it favoured the idea that a small quantity of caloric was requisite, which quantity was carried over from the retort, but which it afterwards lost in the cool vessel. I therefore constructed a small apparatus with which I could repeat the experiments under more favourable circumstances.

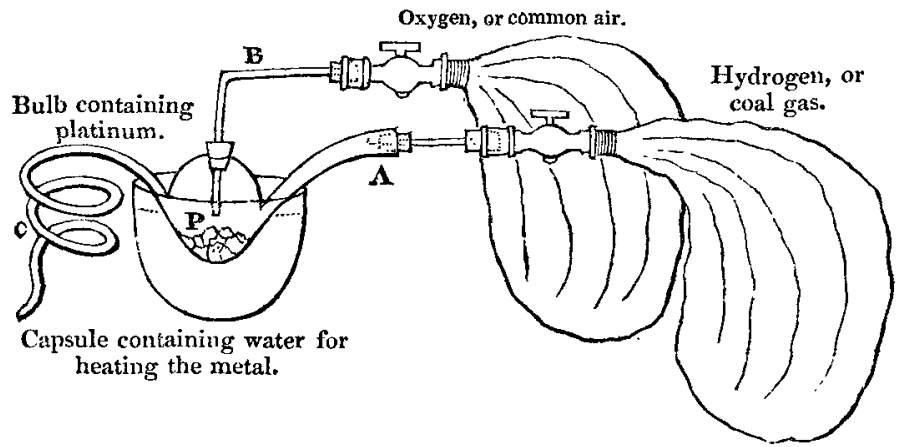

Exp. 3. The apparatus was kept full of hydrogen from the tube $\mathrm{A}$; the metal did not glow at any temperature, and the gas was inflammable as it escaped from the capillary orifice of the 
tube C. A stream of common air was made to act on the metal through the perpendicular tube $B$; it now glowed and continued to do so as long as both streams were continued; when either failed, it immediately cooled; while the metal continued red hot, there was no inflammable gas issuing from the tube $\mathbf{C}$, while water rapidly condensed within it.

In these experiments, the bulb containing the platinum was placed in water at the respective temperatures of $60^{\circ}, 70^{\circ}, 80^{\circ}$, $90^{\circ}, 100^{\circ}$, and $98^{\circ}$ (blood heat); at the first four no effect was observable, while it was at the last two. After 130 cubic inches of hydrogen had passed, the water in the tubes was driven off by heat, and the apparatus weighed; it had lost $\cdot 08 \mathrm{gr}$., which I attributed to accident; but to prove it, I passed 130 cubic inches more, and upon reweighing there was no further diminution.

Exp. 4. The bladders were now changed so that the platinum was in an atmosphere of common air; there was no action at any temperature; but as soon as hydrogen was passed down the tube $\mathrm{B}$, and the platinum was heated to $98^{\circ}$ or $100^{\circ}$; the gases were condensed as before.

Exp. 5. Coal gas mixed with common air was next passed through the tube $\mathbf{B}$ ( $\boldsymbol{A}$ being stopped); it caused the metal to glow, but not until the temperature was much increased. I did not ascertain the exact point, as I consider that it would vary with different proportions.

Exp. 6. The tube $\mathrm{B}$ was then connected with the gas blowpipe and a fine stream admitted, taking care to avoid explosion or inflammation; at $100^{\circ}$ it glowed as before. If in either of the foregoing cases any moisture was present upon the metal, no action took place; whereas the combination was effected more readily and at a lower temperature, when the experiment was repeated a second time within a short time after the first, which I suppose was owing to the platinum being a very bad conductor of caloric, and consequently not cooling to the temperature of the surrounding medium within that time. I found that the same platinum might be used for any length of time, with the precaution of asing it dry.

Imagining that the effect might be electrical, I placed some of the metal in a platinum foil cup on Bennett's electrometer; it glowed in the parts not adjoining the foil, but no signs of electricity were observable.

To try if it was owing to the nonconducting power, I passed a stream of the gases upon asbestus, which is a nonconductor of caloric and finely divided (but fibrous instead of spongy); but there was no action. 
I tried other finely divided metals, such as lead as precipitated by zinc, and gold and silver as thrown down by copper ; but without success.

From those experiments I am perhaps warranted in concluding,

1st, That no chemical change takes place in the platinum, and therefore I presume its effect to be mechanical:

2nd, That a change does take place in the condition of the gases, which change is their union to form water:

$3 \mathrm{~d}$, That in case the gases have the temperature of $55^{\circ}$, the platinum requires a temperature of $98^{\circ}$ to cause them to unite :

4th, That as the condensation of the gases is the only change in the substances used, we must infer that the greatly increased heat of the platinum arises from that condensation.

I have here pointed out the proximate cause of the heat of the platinum, but the ultimate I have not been able to discover. It is therefore left as a problem to future inquirers, Why platinum in a state of minute division should cause the union of oxygen and hydrogen at $100^{\circ}$, whereas their lowest combining temperature without it is $700^{\circ}$ ?

If the effect of the metal be mechanical, 1 have no doubt that other substances will be found having the same power, although $I$ have not succeeded in selecting them.

The phænomena altogether are singular, and appear intimately connected with aphlogistic phænomena, or at least to stand in the same relation to them as they do to rapid combustion : for instance;

At $100^{\circ}$, spongy platinum causes oxygen and hydrogen to combine.

At $700^{\circ}$, they unite without it silently.

At $800^{\circ}$, explosion attends their combination.

At red heat (about $1000^{\circ}$ ), platinum-, silver- or brass-wire causes carbon, hydrogen, and oxygen to combine, forming water, acetic acid, and resin.

At a white heat, carbon, hydrogen, and oxygen, combine, forming water and carbonic acid.

William Herapath.

LX. On some nerely discovered remarkable Properties of the Protoxide, Oxidized Sulphuret, and Metallic Powder of Platinum. By Professor Dabereiner *

I HAVE already proved that the protoxide of platinum obtained by Edmund Davy's method, has the property of * From Schweigger and Meinecke's Ncues Journal für Chemie, \&c. N.R. band viii. p. 321.
Vol.62. No. 306. Oct. 1823.
O o
causing 